\title{
PENERAPAN ASUHAN KEPERAWATAN KELUARGA TN. P PADA NY.S YANG MENGALAMI PENYAKIT HIPERTENSI DENGAN MASALAH KEBUTUHAN RASANYAMAN NYERI DI WILAYAH KERJA PUSKESMAS PANAMBUNGAN MAKASSAR
}

\author{
Application Of Mr "P" Family Nursing Care In Mrs "S" Who Have The Disease Of Hypertension With \\ The Problem Of Pain At Panambungan Public Health Center Makassar \\ Muhammad Purqan Nur, S.Kep., M.Kes \\ Universitas Muhammadiyah \\ Hp : +6285342533598 \\ Email: muhammad.purqan@unismuh.ac.id
}

\begin{abstract}
ABSTRAK
Latar Belakang : Kejadian hipertensi yang meningkat setiap tahun mengindikasikan bahwa hipertensi perlu dan harus segera ditangani. Fenomena ini perlu ditangani lebih lanjut, demikian juga angka yang relatif sangat rendah. Apabila Penderita hipertensi, tidak ditangani dengan baik, akan mempunyai risiko besar untuk meninggal karena komplikasi kardiovaskular seperti stroke, serangan jantung, gagal jantung, dan gagal ginjal. Penyakit ini menjadi salah satu masalah utama dalam ranah kesehatan masyarakatdi indonesia maupun dunia Tujuan : Memperoleh hasil penerapan asuhan keperawatan pada pasien hipertensi dalam pemenuhan kebutuhan rasa yaman nyeri. Metode: Menggunakan tekhnik wawancara dan observasi Hasil : Bedasarkan hasil pengkajian didapatkan keluhan nyeri pada kepala yang dirasakan seperti tertusuk-tusuk dengan skala nyeri 5 , nyeri hilang timbul, setelah dilakukan pemeriksaan tekanan darah didapatkan hasil 160/100 mmHg. Setelah dilakukan pengkajian maka dilakukan skoring untuk menentukan masalah utama, dan diapatkan bahwa masalah utamnya adalah gangguan rasa nyaman nyeri. Intervensi ditentukan berdasarkan masalah kemudian melakukan tindakan keperawatan berdasarkan rencana yang telah ditetapkan. Implementasi dilaksanakan selama tiga hari dan didapat kan hasil pada akhir bahwa klien masih merasakan nyeri namun sudah berkurang dengan skala nyeri ringan (3).

Kata kunci : Asuhan Keperawatan Keluarga, Hipertensi, gangguan rasa nyaman nyeri.
\end{abstract}

\section{ABSTRACT}

Background: The incidence of hypertension which increases every year indicates that hypertension is necessary and must be addressed immediately. This phenomenon needs to be addressed further, as well as relatively very low numbers. If people with hypertension, not treated properly, will have a greater risk of dying from cardiovascular complications such as stroke, heart attack, heart failure, and kidney failure. This disease is one of the main problems in the realm of public health in Indonesia and the world Objective: To obtain the results of the application of nursing care to hypertensive patients in meeting the needs of a sense of pain. Method: Using interview and observation techniques Results: Based on the results of the study, it was found that complaints of headache were felt as if they were pricked with a 5 scale pain, pain relief arose, after a blood pressure examination was obtained $160 / 100 \mathrm{mmHg}$. After the assessment was carried out scoring was carried out to determine the main problem, and it was found that the main problem was the discomfort of pain. Interventions are determined based on the problem then carry out nursing actions based on a predetermined plan. Implementation was carried out for three days and results were obtained at the end that the client was still feeling pain but had been reduced by a mild pain scale (3).

Keywords: Family Nursing Care, Hypertension, pain relief comfort disorder.

\section{PENDAHULUAN}

Penyakit hipertensi merupakan gejala peningkatan tekanan darah yang kemudian berpengaruh pada organ lain, seperti stroke untuk otak atau penyakit jantung koroner untuk pembuluh darah jantung dan ototjantung.penyakit ini menjadi salah satu masalah utama dalam ranah kesehatan masyarakatdi indonesia maupun dunia. (Ardiansyah, 2012)

Menurut WHO, di seluruh dunia sekitar 972 juta orang atau $26,4 \%$ orang diseluruh dunia mengidap hipertensi, angka ini kemungkinan akan meningkat menjadi $29,2 \%$ di tahun 2025. Dari 972 juta pengidap hipertensi, 333 juta berada di Negara maju dan 639 sisanya berada di Negara berkembang, termasuk Indonesia (Yonata, 2016). Penyakit terbanyak pada usia lanjut berdasarkan Riset Kesehatan Dasar (RISKESDAS) tahun 2013 adalah hipertensi. Dengan prevalensi $45,9 \%$ pada usia 55-64 tahun, 57,6\% 75-74 tahun, dan 63,8\% pada 
usia > 75 tahun (Infodatin Kemenkes RI, 2016)

Angka-angka prevalensi hipertensi di indonesia menunjukkan bahwa didaerah pedesaan masih banyak penderita hipertensi yang belum terjangkau oleh layanan kesehatan. Hal ini masih di tambah dengan tidak adanya keluhan dari sebagian besar penderita hipertensi. Prevalensi terbanyak berkisar antara $6 \%$ sampai dengan $15 \%$, tetapi adapula wilayah dengan angka ekstrem yang rendah, seperti di Ungaran, jawa tengah $(1,8 \%)$ Lembah Baliem Pegunungan .

Kejadian hipertensi yang meningkat setiap tahun mengindikasikan bahwa hipertensi perlu dan harus segera ditangani. Fenomena ini perlu ditangani lebih lanjut, demikian juga angka yang relatif sangat rendah. Apabila Penderita hipertensi, tidak ditangani dengan baik, akan mempunyai risiko besar untuk meninggal karena komplikasi kardiovaskular seperti stroke, serangan jantung, gagal jantung, dan gagal ginjal. (Ardiansyah, 2012).

Secara umum Nyeri merupakan sebagai perasaan tidak nyaman, baik ringan maupun berat.(Mubarak, Indrawati, \& Susanto, 2015)Nyeri bersifat sangat subjektif karena intensitas dan responsnya pada setiap orang berbeda-beda.(Saputra, 2013).

Secara umum Nyeri merupakan sebagai perasaan tidak nyaman, baik ringan maupun berat.(Mubarak, Indrawati, \& Susanto, 2015)Nyeri bersifat sangat subjektif karena intensitas dan responsnya pada setiap orang berbeda-beda.(Saputra, 2013).

Pentingnya peran keluarga dalam mengatasi penyakit hipertensi adalah keluarga menjadi support system dalam kehidupan pasien hipertensi yang membutuhkan perawatan dengan waktu yang lama dan terus-menerus.Agar keadaan yang dialami tidak semakin memburuk dan terhindar dari komplikasi akibat hipertensi. (Ningrum, 2012)

Berdasarkan tingginya Angka kejadian hipertensi, maka penulis akan melakukan studi kasus "penerapan asuhan keperawatan keluarga pada pasien yang menderita penyakit Hipertensi"

\section{METODE PENELITIAN}

Penelitian ini menggunakan metode deskriptif dengan desain studi kasus. Penelitian ini dilakukan di Wilayah Kerja Puskesmas Panambungan Makassar pada bulan Juni 2018. Adapu subjek dalam penelitian ini adalah pasien penyakit hipertensi dengan masalah kebutuhan rasa nyaman nyeri, tidak mengalami gangguan komunikasi dan bersedia menjadi responden

\section{HASIL PENELITIAN}

Berdasarkan hasil Pengkajian dilakukan pada hari kamis tanggal 24 mei 2018 jam 09.30 dirumah keluarga Tn."P" didapatkan hasil Ny."S" istri dari Tn."P" sering mengeluh pusing, tekanan darah 160/100 mmHg, nadi $78 \mathrm{x} /$ menit, pernapasan $22 \mathrm{x} /$ menit suhu $36^{\circ} \mathrm{C}$. Ny. "S" mengatakan sering meneluh sakit kepala nyeri leher pada leher bagian belakang, serta pusing nyeri di rasakan saat tekanan darah meningkat, nyeri seperti tertusuktusuk dengan skala nyeri 5 , nyeri hilang timbul.

Diagnosa keperawatan yang muncul pada Ny. S adalah keperawatan gangguan rasa nyaman nyeri berhubungan dengan ketidakmampuan keluarga mengenal masalah penyakit hipertensi, ditandai dengan data subjektif : klien mengatakan sering mengeluh sakit kepala, nyeri leher pada bagian belakang nyeri di rasakan saat tekanan darah meningkat, nyeri seperti tertusuk-tusuk dengan skala nyeri 5 , nyeri hilang timbul, klien juga mengatakan tidak terlalu memahami masalah kesehatan yang di alaminya. Sedangkan data objektif : Ny."S" Nampak memegang kepala dan leher Nampak meringis, tekanan darah 160/100 mmHg, nadi $78 \mathrm{x} /$ menit, pernapasan $22 \mathrm{x} /$ menit suhu $36^{\circ} \mathrm{C}$, dan keluarga Tn "P" nampak bingung saat di tanya tentang masalah kesehatan yang di alami oleh anggota keluarganya.

Intervensi yang dibuat berdasarkan diagnosa keperawatan adalah observasi 
tanda-tanda vital pasien yang rasionalnya mengetahui keadaan umum pasien, Kaji karaktrtistik nyeri yang rasionalnya Mengetahui karakteristik nyeri pada pasien. Kaji pengetahuan keluarga tentang hipertensi yang rasionalnya supaya keluarga mengetahui penyakit hipertensi, Beri penjelasan pada keluarga tentang pengertian, tanda dan gejala serta perawatan nyeri pada hipertensi yang rasionalnya agar pasien dan keluarga mengetahui pengertian, tanda dan gejala serta perawatan nyeri pada hipertensi, ajarkan teknik relaksasi napas dalam, yang rasionalnya untuk mengurangi rasa nyeri,anjurkan pasien kompres dingin pada dahi atau kepala bagian belakang yang rasionalnya mengetahui cara perawatan nyeri dan mengurangi rasa nyeri.

Setelah diberikan tindakan keperawatan selama 3 hari, evaluasi berdasarkan SOAP, yaitu klien mengatakan nyerinya berkurang dengan skala nyeri 3 , Klien nampak tidak memegang kepala dan leher klien nampak tidak terlalu meringis dan kadang masih merasa pusing, TD $140 / 100 \mathrm{mmHg}$

\section{PEMBAHASAN}

Berdasarkan hasil pengkajian yang telah dilakukan pada keluarga Tn. "P" terutama Ny. "S" ditemukan data Ny. "S" yang sedang berumur 50 tahun yang sering mengeluh sakit kepala, nyeri leher pada bagian belakang. $P$ : nyeri karena tekanan darah tinggi, $Q$ : nyeri seperti tertusuk tusuk. $\mathrm{R}$ : nyeri dirasakan pada leher bagian belakang, skala nyeri $5, \mathrm{~T}$ : nyeri hilang timbul, Ny. "S" mengatakan mempunyai riwayat nyeri sudah lama+10 tahun yang lalu. Pada pemeriksaan fisik ditemukan tanda-tanda vital: TD : 160/100 mmHg, P: $78 \mathrm{x} /$ menit, $\mathrm{N}: 20 \mathrm{x} / \mathrm{menit}$ dan $\mathrm{S}$ : 360C.Berdasarkan data yang ditemukan pada saat pengkajian yakni sama dengan teori.

Menurut Heriana (2014) Nyeri dapat didefinisikan sebagai suatu rasa tidak nyaman, baik ringan maupun berat. Nyeri bersifat sangat individual dan tidak dapat diukur secara subjektif, serta hanya pasien yang dapat merasakan adanya nyeri.Nyeri merupakan mekanisme fisiologis yang bertujuan untuk melindungi diri.Nyeri merupakan campuran reaksi fisik, emosi dan perilaku. Menurut Wilkinson (2016) Nyeri di bagi menjadi 2 jenis yakni nyeri akut dan kronik. Nyeri akut. Nyeri akut merupakan sensori dan emosi yang tidak menyenangkan akibat adanya kerusakan jaringan yang actual atau potensial, atau digambarkan dengan istilah seperti kerusakan (International Association for the Study of Pain) awitan yang tiba-tiba atau perlahan dengan intensitas ringan sampai berat dengan akhir yang dapat di antisipasi atau dapat diramalkan dan durasinya kurang dari enam bulan.Nyeri kronis Nyeri kronis merupakan pengalaman sensori dan emosi yang tidak menyenangkan, akibat kerusakan jaringan aktual atau potensial atau digambarkan dengan istilah kerusakan (International Association for the Study of Pain) awitan yang tiba-tiba atau perlahan dengan intensitas ringan sampai berat dengan akhir yang dapat di antisipasi atau dapat diramalkan dan durasinya lebih dari enam bulan.

\section{KESIMPULAN}

1. Berdasarkan pengkajian dan pengumpulan yang telah dilakukan didapatkan masalah kesehatan yaitu Gangguan rasa nyaman nyeri berhubungan dengan ketidakmampuan keluarga mengenal masalah penyakit hipertensi.

2. Setelah dilakukan skoring maka masalah yang menjadi prioritas utama adalahGangguan rasa nyaman nyeri berhubungan dengan ketidakmampuan keluarga mengenal masalah penyakit hipertensi.

3. Intervensi dan implementasi yang telah dilaksanakan adalah mengobservasi tanda-tanda vital pasien, mengkaji karaktrtistik nyeri, mengkaji pengetahuan keluarga tentang hipertensi, memberi penjelasan pada keluarga tentang pengertian, tanda dan gejala serta perawatan nyeri pada hipertensi yang, mengajarkan teknik relaksasi napas dalam,menganjurkan pasien kompres dingin pada dahi atau kepala bagian belakang. 
4. Setelah melakukan asuhan dengan tujuan dan kriteria hasil yang keperawatan, masalah keperawatan pada keluarga Tn.R teratasi sesuai ditetapkan.

\section{DAFTAR PUSTAKA}

Ardiansyah, M. (2012). Medikal Bedah Untuk Mahasiswa. Jogjakarta: Diva Press

Dharma, K. K. (2011). Metodologi Penelitian Keperawatan Panduan Melaksanakan dan Menerapkan Hasil Penelitian. Jakarta: Trans Info Media .

Fadila. (2012). Buku Ajar Keperawatan Keluarga Dilengkapi Aplikasi Kasus Askep Keluarga Terapi Herbal Dan Terapi Modalitas. Yogyakarta: Nuha Medika.

Harmoko. (2012). Asuhan Keperawatan Keluarga. Yogyakarta: Pustaka Pelajar.

Heriana, P. (2014). Buku Ajar Kebutuhan Dasar Manusia. Tangeran Selatan: Binapura Aksara.

Mubarak, W. I., Indrawati, L., \& Susanto, J. (2015). Buku Ajar IImu Keperawatan Dasar. Jakarta: Salemba Medika.

Nurarif, A. H., \& Kusuma, H. (2015). Aplikasi Asuhan Keperawatan Berdasarkan Diagnosa Medis \& NANDA NIC-NOC Jilid 2. Jogjakarta: Mediaction.

Riyadi, S. (2011). Keperawatan Medikal Bedah. Yogyakarta: Pustaka Pelajar.

Saputra, L. (2013). Catatan Ringkas Kebutuhan Dasar Manusia. Tangeran Selatan: Binapura Aksara.

Saryono, \& Widianti, A. T. (2011). Catatan Kuliah Kebutuhan Dasar Manusia (KDM). Yogyakarta: Nuha Medika.

Susanto, T. (2012). Buku Ajar Keperawatan Kekuarga Aplikasi Teori Pada Praktik Asuhan Keperawatan Keluarga. Jakarta: CV Trans Info Media.

Utaminingsih, W. R. (2015). Mengenal \& Mencegah Penyakit Diabetes, Hipertensi, Jantung dan Strok Untuk Hidup Lebih Berkualitas. Yogyakarta: Media IImu.

Wilkinson, J. M. (2016). Diagnosis Keperawatan Diagnosis NANDA-I, Intervensi NIC, Hasil NOC Edisi 10. Jakarta: Buku Kedokteran EGC.

Destiara, H. Z., Riris, D.R. (2017). Hubungan Pengetahuan dan Riwayat Hipertensi Dengan Tindakan Pengendalian Tekanan Darah Pada Lansia. Jurnal.Berkala.Epidemolog. Volume.5.Nomor.2.Diakses, dari.https://e journal.unair.ac.id/JBE/article/

Syiddatul, B. (2017). Pengaruh Pemberian Kompres Hangat Jahe Tehadap Skala Nyei Kepala Hipertensi Pada Lansia Di Posyandu Lansia Karang Werdha Rambutan Desa Burneh Bangkalan.Jurnal Kesehatan,Volume.5.No.1.Diakses,dari.https://publikasi.polije.ac.id

M. Isra.K.H.B., Billy. J. K., Mulyadi. (2017) Hubungan Derajat Keluarga Dengan Derajat Hipertensi Pada Pasien Hipertensi Di Puskesmas Ranomuut Kota Menado.e-Journal keperawatan (eKP).volume.5. Nomor.1. diakses.dari.https://media.neliti.com. 